\title{
Lights, Camera, Learn: Understanding the Role of Lecture Capture in Undergraduate Education
}

Daniel J. Mallinson, Stockton University

Zachary D. Baumann, Pennsylvania State University

ABSTRACT Lecture-capture software allows instructors to record their class presentations for students to review as necessary. Although this technology has long been considered too expensive for large-scale use, it is quickly becoming ubiquitous and deployable using ordinary computers and consumer-grade software. Using survey and final-grade data from a three-semester trial in a large introductory-level political science course, the authors demonstrate students almost universally approve of the technology and support its use in future classes. Students are most likely to use recordings when they study for exams and catch up on material after being absent from class. Additionally, certain subgroupsprimarily international students and those who are performing poorly in the class-are more likely to watch archived recordings. However, these data demonstrate that positive evaluations and increased usage may not translate into better grades; viewing lectures does not appear to substantially improve individual performance.

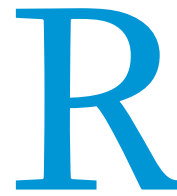

ecording classes for consumption outside of the lecture hall is not a new idea in academia. A quick search of video-sharing sites, as well as the web pages of prominent universities, reveals a treasure trove of content accessible to students and interested laypeople. Today, the cost of producing lecture recordings has been greatly reduced with "out-of-the-box" solutions sold by several vendors. These products can be programmed and managed remotely, requiring instructors only to show up on time, turn on their microphone, and begin talking. Although lecture capture is far less difficult and costly compared to previous solutions, should instructors rush to implement it in their own classroom? This study examines more systematically the benefits offered by this technology.

\section{USING LECTURE CAPTURE IN THE CLASSROOM}

The emergence of new, user-friendly recording methods in recent years has allowed for innovation in delivering course content. Lecture capture traditionally involves the video recording of slides or chalkboard presentations along with an instructor's

Daniel J. Mallinson is an assistant professor at Stockton University. He can be reached at Daniel.Mallinson@stockton.edu.

Zachary D. Baumann is a lecturer in political science at Pennsylvania State University. He can be reached at zdb1@psu.edu. narration. Outside of the classroom, personal screencasts now allow presenters to record information displayed on their monitors and voiceover, obviating the need for special rooms, complicated editing software, and trained videographers. Recordings now can be made both in and out of the classroom with limited overhead, which allows instructors to archive class presentations and provide additional assistance when material proves difficult to understand (Green, Pinder-Grover, and Millunchick 2012, 717-18).

During the fall 2011, fall 2012, and spring 2013 semesters, we participated in a university-led trial of lecture-capture software in our 350-student introduction to American politics course. This course, which is taught once each semester using a traditional lecture format, satisfies general-education requirements across the university and is a prerequisite for our department and others. Students are allowed to write a series of essays or to complete several exams to earn their final grade. Clickers (i.e., a student-response system) are used during class to assess levels of understanding and promote engagement with the material.

We used software from two vendors, Echo36o and Panapto, during the trial period. Both products operate similarly: software is downloaded to classroom computers and programmed to begin and end recording coinciding with the class session. A lapel microphone is also programmed to feed into the computer's recording of the material displayed onscreen. The resulting file captures the lecturer's voice as well as material shown using the 
video projector. After the class session ends, the recordings are automatically uploaded, converted into a single digital file, and placed on a private server for students to view.

To understand how students used and evaluated lecturecapture recordings, we conducted surveys of our classes each semester (i.e., fall 2011, fall 2012, and spring 2013). With approval from the Institutional Review Board and written consent from students, we combined survey responses with their grades in the
(71\%) and catching up after missing a class $(67 \%)$. Of these respondents, $40 \%$ reported using it to regularly review content; only $17 \%$ used it to fill in gaps from class. This suggests that students use the software episodically for specific purposes rather than to regularly review material.

Further evidence is drawn from how frequently students report watching lectures. Figure 1 shows the self-reported number of viewings for each respondent. ${ }^{2}$ The majority (70\%) of students

\section{Recordings can be thought of best as a resource that some students take advantage of when it is beneficial to them.}

course. Thirty-two percent of our students agreed to participate across the three surveys and 230 of the 320 total respondents reported using lecture recordings at least once during the semester. ${ }^{1}$ The survey included questions that measured their overall attitude about course structure, use of technology, demographic characteristics, and engagement and interest in politics. We also included a series of questions that specifically addressed why students chose to use lecture-capture recordings, how often they used them, and if they believed that the technology was helpful in learning the material.

To provide a context for these results, table 1 presents information about the students who participated in the survey. They were evenly divided between males and females and the majority was freshmen and sophomores. Most of the students were born in the United States; $12 \%$ were born outside of the country. In terms of racial identification, most respondents were white, and the racial breakdown reflected the levels of diversity at the University Park campus of Pennsylvania State University (University Budget Office 2014). Finally, in terms of academic affiliation within the university, the largest group of students in the course was from the College of the Liberal Arts. However, students came from diverse disciplines, including education, business, engineering, health, and earth sciences, among others.

\section{HOW OFTEN ARE THE RECORDINGS USED?}

Lecture-capture research often focuses on the science, technology, engineering, and mathematics (STEM) fields with fewer studies of their usefulness in the social sciences and humanities. The results indicate that students make a conscious decision to watch the recordings or abstain from doing so (Billings-Gagliardi and Mazor 2007). Recordings can be thought of best as a resource that some students take advantage of when it is beneficial to them. Moreover, students are strategic when determining which lectures to watch and for how long (Billings-Gagliardi and Mazor 2007; Gosper et al. 2007; Green, Pinder-Grover, and Millunchick 2012; Lauer, Müller, and Trahasch 2004; Owston, Lupshenyuk, and Wideman 2011; von Konsky, Ivins, and Gribble 2009). Specifically, students use recordings to study for exams (Chandra 2007; Gosper et al. 2007), to catch up on lectures they may have missed (Gosper et al. 2007; von Konsky, Ivins, and Gribble 2009), and to review material that they find difficult to understand (Green, Pinder-Grover, and Millunchick 2012; Owston, Lupshenyuk, and Wideman 2011).

These extant findings replicate well within a social science context. Examining our survey responses, we find that the majority of students report using lecture capture when studying for exams who reported using lecture capture at least once did so between 1 and 10 times during the span of the semester. This means that most users viewed less than one third of the available lectures.

\section{WHO USES THE LECTURE RECORDINGS?}

We also were interested in particular subpopulations within the class that may benefit from this lecture-capture resource. Specifically, previous research revealed that international students

Table 1

Profile of the Lecture-Capture Survey Respondents

Variable and Categories

Percentage*

\begin{tabular}{|c|c|c|}
\hline Used Lecture & Yes & 72 \\
\hline Capture & No & 28 \\
\hline \multirow[t]{2}{*}{ Sex } & Male & 50 \\
\hline & Female & 47 \\
\hline \multirow[t]{4}{*}{ Age } & $18-19$ & 53 \\
\hline & $20-21$ & 40 \\
\hline & $22-23$ & 5 \\
\hline & 24 and older & 1 \\
\hline \multirow[t]{4}{*}{ Year in School } & Freshman & 26 \\
\hline & Sophomore & 40 \\
\hline & Junior & 24 \\
\hline & Senior & 10 \\
\hline Born in the & Yes & 88 \\
\hline United States & No & 12 \\
\hline \multirow[t]{5}{*}{ Race } & African American & 5 \\
\hline & Asian & 8 \\
\hline & Hispanic & 5 \\
\hline & White & 76 \\
\hline & Other & 6 \\
\hline Academic & Liberal Arts & 41 \\
\hline \multirow[t]{4}{*}{ Program } & Health and Human Development & 11 \\
\hline & Education & 9 \\
\hline & Business & 7 \\
\hline & Other & 32 \\
\hline
\end{tabular}

Notes: $\mathrm{N}=320 .{ }^{*}$ Not all categories sum to $100 \%$. This represents either nonresponses or "other" answers. 


\section{Figure 1}

\section{Self-Reported Number of Lecture-Capture Views}

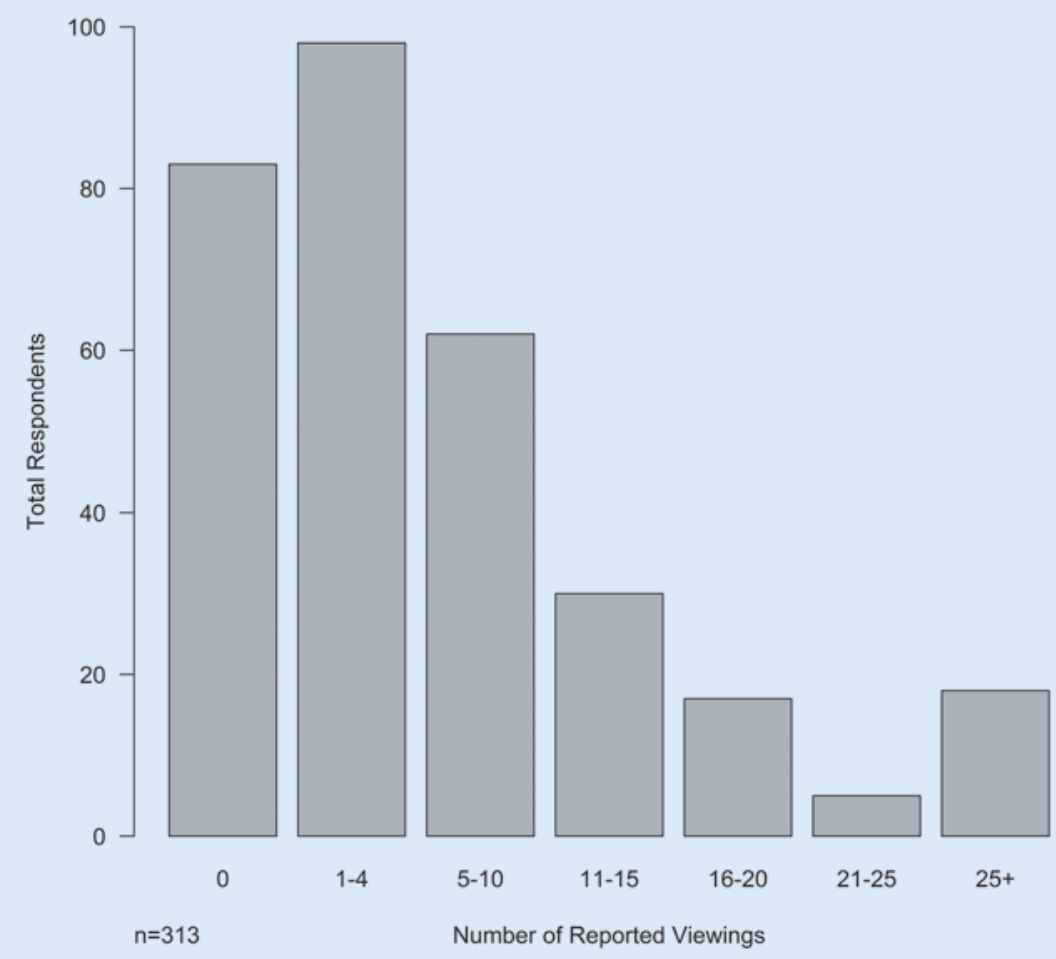

substantial usage differences among students on the basis of gender, age, and year in school.

In addition to assessing why students use lecture capture, we asked why they did not. 3 Consistent with other research (Billings-Gagliardi and Mazor 2007; Chandra 2007), the majority of nonusers $(53 \%)$ reported that they learned better from reading the textbook and/or attending class, and they did not believe that lecture recordings enhanced their understanding of the material. Furthermore, $38 \%$ explained that they did not have enough extra time outside of class to view the lectures. Finally, $2 \%$ of nonusers reported technical problems as the reason that they chose not to use the recordings.

\section{WHAT IS THE EFFECT OF VIEWING LECTURE RECORDINGS?}

Scholars often have noted that students positively evaluate the

comprise one subgroup that tends to take advantage of recordings at a higher rate than their US-born peers (Pinder-Grover, Green, and Millunchick 2011). In particular, international students face multiple hurdles in attaining mastery over course content. Of greatest concern is that they often are learning language and content simultaneously, making the acquisition of new concepts difficult on the first pass. Therefore, we wanted to understand how these students use lecture recordings.

We had only 37 responses from students not born in the United States, but they provided initial insight about the utility of lecture capture for this subpopulation. Of the 37 students, $30(81 \%)$ reported using lecture capture at least once during the semester, which is higher than the $72 \%$ of total students reporting usage. Furthermore, there is evidence that the frequency with which international students are using lecture capture differs. More than $25 \%$ of international student users reported using the software more than 25 times during the semester, whereas only $5 \%$ of US-born students were in the highest usage category. At the other end of the spectrum, $25 \%$ of international students reported using lecture capture only one to five times, whereas a full $45 \%$ of non-international students were in this category. This suggests that international students are relying on the software on a more regular basis than US-born students.

There also were differences in the reported reasons that international students used recordings. A higher proportion used lecture capture to review content after class (48\% versus $38 \%$ ); however, a lower proportion used it to study for exams (52\%versus $69 \%$ ) and to catch up after missing a class ( $55 \%$ versus $73 \%$ ). It is interesting that rates of software use due to an inability to hear the instructor are similar between the two groups (19\% versus $17 \%)$. Other than for international students, there were few availability of lecture recordings (Dey, Burn, and Gerdes 2009; Gosper et al. 2007; Green, Pinder-Grover, and Millunchick 2012; von Konsky, Ivins, and Gribble 2009). Our survey posed a series of questions regarding satisfaction with the lecture-capture technology used in our classes. A majority (69\%) of respondents was either very or somewhat satisfied with the technology. Furthermore, three quarters of students would recommend using lecture capture in future classes. Conversely, only $7 \%$ was strongly or somewhat dissatisfied with the lecture-capture system. Among the 21 dissatisfied students, 18 reported using it either never or one to four times; only one student was a high user (i.e., 25 or more reported viewings). Most of the complaints registered in an open-ended question about lecture-capture satisfaction were about technological issues. These students noted problems that the university had with its Panopto and Echo 360 implementation as well as problems with their individual computer.

In addition to student evaluations, several approaches have been undertaken to assess the effect that lecture recordings have on grades. On a basic level, research indicates that low-performing students may be among those most likely to watch the recordings (Owston, Lupshenyuk, and Wideman 2011; Pinder-Grover, Green, and Millunchick 2011). Furthermore, they will be more likely to consume entire lectures, sometimes repeatedly, compared to their higher-performing counterparts who view only specific portions. Although these results often were based on self-reported course grades, we can examine this relationship using actual grades earned by students.

Figure 2 shows the final course-grade distributions within each category of lecture-capture usage. The figure shows that for most categories, the average grade remains in the mid to high 8os; however, this changes when reviewing the highest reported users. 
Not only does the average grade decrease to $75 \%$; the grades also become more dispersed when compared to other categories. This is due partly to two students who earned final grades below $60 \%$; however, when their scores were removed, the average (82\%) was still the lowest category. We believe that figure 2 explains an interesting point about lecture-capture users. Across many of the categories, both average and above-average students were using the technology. Consistent with earlier findings, however, poorerperforming students were consuming the most. This could suggest that lecture recordings are not helpful; however, we also cannot rule out the possibility that the grades of our poorestperforming students would have been much lower without this resource. Further studies that allow for the random assignment of lecture recordings may help us to better understand this relationship. viewing corresponds to a $2.5 \%$ point decrease in a student's final grade. However, when attendance is included in the model of performance, it has a statistically significant and positive effect on grades, and lecture-recording viewings fail to achieve traditional levels of statistical significance.

These results do not lead us to conclude that viewing lectures has a substantive impact on performance in this class. First, examining the fit of each model demonstrates that including attendance in the equation explains more variation in grade outcomes. Second, the negative effect of lecture-capture viewings in Model 1 likely reflects the increased probability that those students who are struggling in the class are watching more, either to catch up on missed material or because they do not understand the concepts after their first exposure. Third, Model 2 shows that when viewings are included with other relevant covariates, rewatching

\section{Across many of the categories, both average and above-average students were using the tech- nology. Consistent with earlier findings, however, poorer-performing students were consum- ing the most.}

By using the final grades of students in these classes, however, we were able to gain insight about the connection between lecture recordings and grade outcomes. Using final course grades as the dependent variable, we regressed these values on their viewership habits (i.e., self-reported), attendance in class (i.e., measured by Clickers), and a variety of other sociodemographic variables. Table 2 presents the results of two ordinary least squares equations: the first omits attendance from the calculation of grade outcomes; the second includes it. Model 1 reveals that lecture-capture viewing can have a statistically significant but negative impact on a student's grade. An increase in one category of lecture-capture the presentation does not affect course grades at a statistically significant level. Although recordings are evaluated highly by students and recommended for future classes, these data do not suggest that they greatly impact overall performance in this class.

\section{CONCERNS ABOUT ATTENDANCE}

Given that such a significant number of students $(67 \%)$ reported using lecture capture to catch up when they missed a class, it is a realistic concern that this technology could be used as a substitute for attending class. The extant research does not yield conclusive results. Some studies found that it has little to no impact (Chandra 2007; von Konsky, Ivins, and Grible 2009) and others showed a modest decline in the percentage of students who attend class (Billings-Gagliardi and Mazor 2007). In other research, it was found that about one third of students would opt for video-only lectures, if given the choice (Lauer, Müller, and Trahasch 2004). In general, we expect students to be strategic, attending class when it proves beneficial and using this resource when it provides the best payoff.

Our data allow us to address this concern. On average, students who used lecture capture attended fewer classes $(\mathrm{M}=81.02$, $\mathrm{SD}=21.08)$ than those who did not use the resource $(\mathrm{M}=90.71$, $\mathrm{SD}=13.78), \mathrm{t}(277)=4.51, p<$ o.oo1. One possible explanation is that, as expected, students were skipping class and using lecture captures as a substitute. 
Table 2

Results of Ordinary Least Squares Model of Final Grade Outcomes

\begin{tabular}{lcr} 
Variable & Model 1 & \multicolumn{1}{c}{ Model 2 } \\
\hline White & $2.489(1.678)$ & $1.303(1.509)$ \\
\hline Male & $-1.337(1.136)$ & $-0.830(1.019)$ \\
\hline Born in the United States & $0.181(2.047)$ & $1.811(1.844)$ \\
\hline Attendance & & $0.211^{* * *}(0.027)$ \\
\hline Lecture-Capture Viewings & $-2.523^{*}(1.288)$ & $-0.291(1.187)$ \\
\hline College Grade Point Average & $3.307^{* * *}(0.679)$ & $2.860^{* * *}(0.610)$ \\
\hline Mother's Level of Education & $-0.379(0.569)$ & $-0.238(0.509)$ \\
\hline Father's Level of Education & $1.238^{* *}(0.587)$ & $1.340^{* *}(0.526)$ \\
\hline Year in School & $-1.206^{*}(0.661)$ & $-0.634(0.596)$ \\
\hline Political Interest & $1.628^{* * *}(0.574)$ & $2.165^{* * *}(0.518)$ \\
\hline Intercept & $72.064^{* * *}(3.881)$ & $50.241^{* * *}(4.441)$ \\
\hline $\mathrm{N}$ & 257 & 257 \\
\hline Adjusted R & 0.168 & 0.333 \\
\hline
\end{tabular}

Notes: Standard errors are shown in parentheses. ${ }^{*} p<0.10 ;{ }^{* *} p<0.05 ;{ }^{* *} p<0.01$.

Alternatively, this could be an artifact of the legitimate use of lecture capture in the event of excused absences. Although our design does not allow us to definitively assess the relationship between recordings and attendance, we can offer preliminary insights.

First, if students can obtain from the recordings all of the necessary information to do well in class and they do not derive any additional benefit from attending in person, they likely will stay home. However, if they find added value in attending, they will continue coming to class (Billings-Gagliardi and Mazor 2007; Chandra 2007). However, this raises a relevant pedagogical question: What is the value of students attending class in person? Dey, Burn, and Gerdes (2009) demonstrated that being in the lecture hall does not guarantee academic success. Utilizing an experimental design, they found that students who watched only video lectures scored better on an exam when compared to those who attended the same lecture in person. Therefore, it is important to consider why compelling physical attendance is better than only watching videos. If the goal is to maximize the number of students in the classroom and still use lecture recordings, then these results suggest that it is best to think about designing recordings and class time as a supplement rather than a substitute and to consider incentives for attending in person.

\section{CONCLUSIONS}

Recording lectures for student review has become easier with the emergence of new hardware and software, regardless of class or school size. Previous scholars found that students approve of course recordings, and some suggested that it could lead to higher grades (Dey, Burn, and Gerdes 2009; Green, Pinder-Grover, and Millunchick 2012; Pinder-Grover, Green, and Millunchick 2011; von Konsky, Ivins, and Gribble 2009). Whereas most research has focused on the use of this technology in STEM fields, we think it also is important to consider its usefulness in political science. As opposed to many of the courses studied previously, an introductory political science course is more likely to be a core or major degree-program requirement. This means that students are likely to have different levels of motivation for completing the course; they are diverse in their prior knowledge and exposure to the material; and they have variable levels of interest in the topics.

Our results reveal that students will use lecture recordings to study for exams, to clarify concepts and theories, and to review material they may have missed in class. Some students are more likely to take advantage of these recordings than others. International students and those who have difficulty with the material, for instance, may find this resource helpful for learning the relevant content. The efficacy of lecture recordings, however, appears to be mixed. Although students almost universally approve of archiving classes for later consumption, the impact on grades appears to be minimal at best. Future research designs that randomly assign access to recordings may better assess efficacy in this respect. Finally, we urge instructors to consider carefully their purpose for recording lectures and to be mindful of how they will be used by strategically acting students.

\section{NOTES}

1. The response rate was $40 \%$ in the fall 2011 semester, $43 \%$ in fall 2012 , and $15 \%$ in spring 2013. The same survey was administered each semester, about two weeks before the end of the term. Although the same protocol was followed in each semester, the response rate for spring 2013 was noticeably lower than its predecessors. In examining these responses, however, we did not find answers that deviated substantially from those during the previous two terms.

2. We asked: "About how many times did you watch the lecture recordings this semester?" Respondents chose responses from discrete categories of $0,1-4$ 5-10, 11-15, 16-20, 21-25, and more than 25.

3. We asked about reasons for nonuse only in the fall 2012 and spring 2013 surveys; 83 students did not use lecture capture.

\section{REFERENCES}

Billings-Gagliardi, Susan, and Kathleen M. Mazor. 2007. "Student Decisions about Lecture Attendance: Do Electronic Course Materials Matter?" Academic Medicine 82 (10): $\mathrm{S}_{73}-\mathrm{S}_{7} 6$.

Chandra, Surendar. 2007. "Lecture Video Capture for the Masses." Paper presented at the Association for Computing Machinery 12th Annual Conference on Innovation and Technology in Computer Science Education, 276-80. Dundee, Scotland, June 23-27.

Dey, Eric L., Helen E. Burn, and David Gerdes. 2009. "Bringing the Classroom to the Web: Effects of Using New Technologies to Capture and Deliver Lectures." Research in Higher Education 50 (4): 377-93.

Gosper, Maree, Margot McNeill, Karen Woo, Rob Phillips, Greg Preston, and David Green. 2007. "Web-Based Lecture-Recording Technologies: Do Students Learn from Them?" Paper presented at Educause Australasia. Melbourne, Australia, May 29-2. Available at http://www.mq.edu.au/ltc/altc/wblt/docs/ dissemination/Educause_Gosper.pdf. Accessed January 27, 2014.

Green, Katie R., Tershia Pinder-Grover, and Joanna Mirecki Millunchick. 2012. "Impact of Screencast Technology: Connecting the Perception of Usefulness and the Reality of Performance." Journal of Engineering Education 101 (4): 717-37.

Lauer, Tobias, Rainer Müller, and Stephan Trahasch. 2004. "Learning with Lecture Recordings: Key Issues for End-Users." Paper presented at the Institute of Electrical and Electronics Engineers International Conference on Advanced Learning Technologies. Joensuu, Finland.

Owston, Ron, Denys Lupshenyuk, and Herb Wideman. 2011. "Lecture Capture in Large Undergraduate Classes: Student Perceptions and Academic Performance." The Internet and Higher Education 14 (4): 262-8.

Pinder-Grover, Tershia, Katie R. Green, and Joanna Mirecki Millunchick. 2011. "The Efficacy of Screencasts to Address the Diverse Academic Needs of Students in a Large Lecture Course." Advances in Engineering Education 2 (3): 1-28.

University Budget Office, Pennsylvania State University. University Park Table B2, Common Data Set 2012-2013. Available at http://www.budget.psu.edu/CDS/ default.aspx?AY= 20122013. Accessed January 27, 2014.

von Konsky, Brian R., Jim Ivins, and Susan J. Gribble. 2009. "Lecture Attendance and Web-Based Lecture Technologies: A Comparison of Student Perceptions and Usage Patterns." Australasian Journal of Educational Technology 25 (4): 581-95 